\title{
Experience with the Novacor left ventricular assist system as a bridge to cardiac transplantation, including the new wearable system
}

The three components of the Novacor left ventricular assist system, compact controller, battery, and back-up battery, have been miniaturized in the development of the wearable system. Therefore patients can be fully mobilized receiving mechanical circulatory support while awaiting heart transplantation. Between February 1992 and April 1994 a total of eight patients with decompensated heart failure (6 dilated cardiomyopathy, 1 acute myocarditis, 1 ischemic cardiomyopathy) were treated with the Novacor left ventricular assist system. In the most recent four cases the wearable system (N100P) was used. Patients' ages ranged from 17 to 49 years. In five patients severe failure of the right side of the heart was present at the time of implantation. Hemodynamic stabilization was achieved in all patients during the 2 to 122 days (mean $30.8 \pm \mathbf{4 2 . 5}$ days) of support. The following parameters were measured on average before and 24 hours after implantation of the left ventricular assist system: mean arterial pressure $70 \pm$ 11 versus $87 \pm 13 \mathrm{~mm} \mathrm{Hg}(p<0.05)$, cardiac index $1.71 \pm 0.42$ versus $3.23 \pm 0.74 \mathrm{~L} / \mathrm{min} / \mathrm{m}^{2}(p<0.05)$, pulmonary capillary wedge pressure $27.1 \pm 4.4$ versus $9.9 \pm 5.2 \mathrm{~mm} \mathrm{Hg}(p<0.01)$, mean pulmonary pressure $41 \pm 9$ versus $27 \pm 6 \mathrm{~mm} \mathrm{Hg}(p<0.05)$, and right ventricular ejection fraction $16.7 \% \pm 10.3 \%$ versus $22.0 \% \pm 11.6 \%$ (not significant). Patients who received the wearable system were capable of managing their own power supply during the bridging period and were able to walk to the hospital park and shopping area. One patient had a serious pulmonary infection, which was treated successfully, and two patients had a cerebrovascular accident, which resolved in one and resulted in a minor residual deficit in the other. All eight patients received a heart transplant. One patient died early after transplantation and seven patients are alive and well. In summary, the wearable Novacor left ventricular assist system provides major advantages regarding quality of life of patients during mechanical circulatory support. However, there is a remaining risk of thromboembolism despite anticoagulation therapy. (J THORAC CARDIOVASC SURG 1995;109:74-80)

Herbert O. Vetter, $\mathrm{MD}^{\mathrm{a}}$ (by invitation), Hans G. Kaulbach, $\mathrm{MD}^{\mathrm{a}}$ (by invitation), Christoph Schmitz, $\mathrm{MD}^{\mathrm{a}}$ (by invitation), Andreas Forst, $\mathrm{MD}^{\mathrm{b}}$ (by invitation), Peter Überfuhr, MD ${ }^{a}$ (by invitation), Eckart Kreuzer, MD ${ }^{\mathrm{a}}$ (by invitation), Michael Pfeiffer, $\mathrm{MD}^{\mathrm{c}}$ (by invitation), Paolo Brenner, $\mathrm{MD}^{\mathrm{a}}$ (by invitation), Oliver Dewald, $\mathrm{MS}^{\mathrm{a}}$ (by invitation), and Bruno Reichart, MD ${ }^{\mathrm{a}}$ (by invitation), Munich, Germany

Sponsored by Robert W. M. Frater, MD, Bronx, N.Y.

From the Department of Cardiac Surgery ${ }^{\mathrm{a}}$ (Head Prof. Dr. B. Reichart), the Institute of Anesthesiology ${ }^{\mathrm{b}}$ (Head Prof. Dr. K. Peter), and the Institute of Clinical Chemistry ${ }^{c}$ (Head Prof. Dr. D. Seidel), University of Munich, Grosshadern Hospital Munich, Germany.

Read at the Seventy-fourth Annual Meeting of The American Association for Thoracic Surgery, New York, N.Y., April 24-27, 1994.

Address for reprints: Herbert O. Vetter, MD, Department of Cardiac Surgery, Grosshadern Medical Center, University of Munich, 81366 Munich, Germany.

Copyright (C) 1995 by Mosby-Year Book, Inc.

$0022-5223 / 95 \$ 3.00+0 \quad \mathbf{1 2 / 6 / 6 0 2 5 0}$
C ardiac transplantation has become an accepted method in clinical therapy for end-stage heart disease. However, the shortage of donors is responsible for a high percentage of patients dying while awaiting heart transplantation. Within the past decade electrically powered ventricular assist devices ${ }^{1}$ and pneumatically driven artificial hearts ${ }^{2}$ have been used in clinical programs to rescue critically ill cardiac transplant candidates. Because the average waiting time for a donor heart increased during the past few years this situation has resulted in pro- 


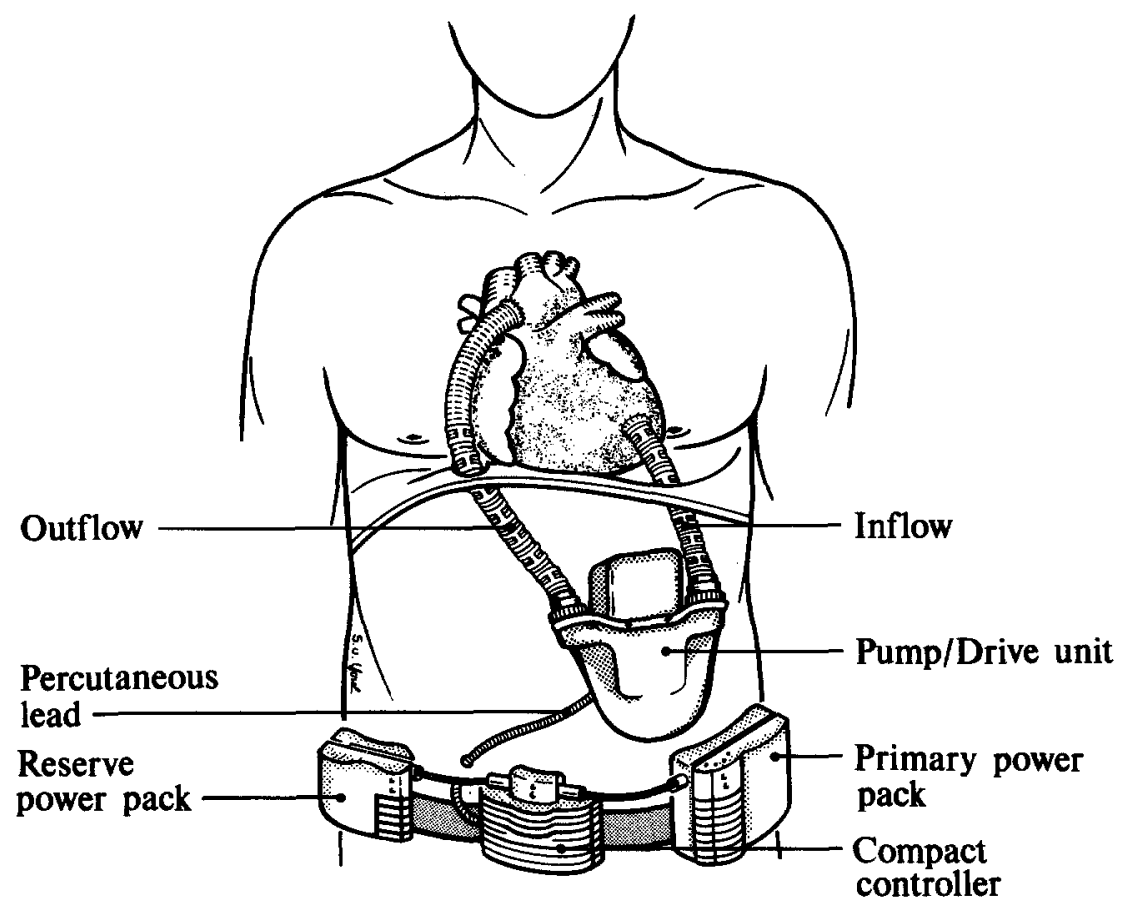

Fig. 1. Wearable Novacor LVAS.

longed periods of mechanical circulatory support. However, the incidence of thromboembolism remains a major threat in patients who receive long-term support. Anticoagulation protocols and changes in device design are important factors for the outcome of such patients. ${ }^{3}$ Since 1993 the large external console of the Novacor left ventricular assist system (LVAS) has been miniaturized: the result is a system that can be worn on a belt and that allows a higher degree of mobility and quality of life to patients during the waiting period.

\section{Material and methods}

Assist device. The Novacor N100 LVAS (Novacor Division, Baxter Healthcare Corp., Oakland, Calif.), is an electromagnetically actuated implantable pump that consists of a seamless one-piece smooth polyurethane sac that is bonded to symmetrically opposed dual pusher-plates. The housing is a lightweight shell that incorporates bovine pericardial valve fittings and an energy converter. The implanted pump unit is connected to the extracorporeal control console or wearable controller via a percutaneous lead (Fig. 1). Inflow and outflow Dacron fabric grafts, which both perforate the diaphragm, connect the pump to the left ventricular apex and to the ascending aorta. The maximal stroke volume of $70 \mathrm{ml}$ can provide a pump output up to $10 \mathrm{~L} / \mathrm{min}$. With operation in synchronous counterpulsation cardiac rates of up to 240 beats $/ \mathrm{min}$ can be achieved. ${ }^{4}$
The external console used for the first four patients weighed approximately $150 \mathrm{~kg}$ and usually required an engineer or other assistant to help the patient move about. The new wearable controller and external batteries are substantially smaller and weigh approximately $3 \mathrm{~kg}$. They can be either worn on a belt or carried in a shoulder bag for much easier mobility. Untethered operation is achieved when two direct-current power sources are connected (Fig. 1). With batteries, the patient is fully mobile up to 6 hours and independent of alternating-current power or monitor. This is a major step in getting the patients fully ambulatory to improve quality of life during mechanical circulatory support.

Patients. Between February 1992 and April 1994 the Novacor LVAS was implanted in eight patients as a bridge to cardiac transplantation. The wearable system was used for the most recent four patients. Dilated cardiomyopathy in six patients, end-stage ischemic heart disease in one patient, and acute myocarditis in one patient were the underlying diseases when the patients were evaluated as heart transplant candidates. Before Novacor implantation two patients were supported by intraaortic balloon counterpulsation. The mean patient age was $31.6 \pm 12.9$ years (range 16 to 49 years). The average body surface area was $1.83 \pm 0.10 \mathrm{~m}^{2}$ and ranged from 1.72 to $1.98 \mathrm{~m}^{2}$.

The clinical status and hemodynamics of all patients were deteriorating despite inotropic or vasodilator support, or both therapies. Preoperative patient data are given in Table I. Cardiac output and parameters of function of the right side of the heart were evaluated by means of a rapid-response thermodilution catheter. In five of the eight patients right ventricular ejection fraction was 
Table I. Preoperative patient data

\begin{tabular}{|c|c|c|c|c|c|c|}
\hline Patient No. & Age $(y r)$ & Diagnosis & $\begin{array}{c}\text { Body } \\
\text { surface } \\
\text { area }\left(m^{2}\right)\end{array}$ & $\begin{array}{c}\text { Cardiac index } \\
\left(\mathrm{L} / \mathrm{min} / \mathrm{m}^{2}\right)\end{array}$ & $\begin{array}{c}\text { Central venous } \\
\text { pressure } \\
(\mathrm{mm} \mathrm{Hg})\end{array}$ & $\begin{array}{l}\text { Preoperative } \\
\text { inotropic agents }\end{array}$ \\
\hline 1 & 17 & DCM & 1.81 & 1.0 & 34 & $\mathrm{~A}, \mathrm{D}, \mathrm{Db}$ \\
\hline 2 & 16 & $\mathrm{AM}$ & 1.75 & 2.0 & 7 & $\mathrm{~A}, \mathrm{D}, \mathrm{Db}, \mathrm{E}$ \\
\hline 3 & 32 & DCM & 1.87 & 1.3 & 28 & $\mathrm{D}, \mathrm{Db}, \mathrm{NA}$ \\
\hline 4 & 49 & $\mathrm{DCM}$ & 1.72 & 1.5 & 14 & $\mathrm{D}, \mathrm{Db}, \mathrm{IABP}$ \\
\hline 5 & 48 & IHD & 1.98 & 2.0 & 5 & $\mathrm{D}, \mathrm{IABP}$ \\
\hline 6 & 26 & $\mathrm{DCM}$ & 1.81 & 2.2 & 20 & $\mathrm{D}, \mathrm{Db}$ \\
\hline 7 & 25 & $\mathrm{DCM}$ & 1.75 & 1.8 & 20 & $\mathrm{~A}, \mathrm{NA}, \mathrm{D}, \mathrm{Db}, \mathrm{E}$ \\
\hline 8 & 40 & $\mathrm{DCM}$ & 1.95 & 2.0 & 17 & $\mathrm{D}, \mathrm{E}$ \\
\hline Mean $\pm \mathrm{SD}$ & $31.6 \pm 12.9$ & & $1.83 \pm 0.10$ & $1.7 \pm 0.4$ & $18 \pm 10$ & \\
\hline
\end{tabular}

$D C M$, Dilated cardiomyopathy; $A$, adrenaline; $D$, dopamine; $D b$, dobutamine; $A M$, acute myocarditic; $E$, enoximone; $N A$, noradrenaline; $L A B P$, intraaortic balloon pump, $I H D$, ischenic heart disease; $S D$, standard deviation.

only $4 \%$ and in the others the value was $13 \%, 15 \%$, and $16 \%$, respectively. Renal function was reduced with oliguria or anuria and a mean serum creatinine level of $1.50 \pm 0.54 \mathrm{mg} / \mathrm{dl}$. Mean total bilirubin level was $2.11 \pm$ $1.51 \mathrm{mg} / \mathrm{dl}$ and the mean value of aspartate aminotransferase was $198 \pm 246 \mathrm{mg} / \mathrm{dl}$ (range 70 to $660 \mathrm{mg} / \mathrm{dl}$ ) before Novacor LVAS implantation.

Surgical technique. The implantation technique based on suggestions by Oyer and associates ${ }^{5}$ was modified in various steps to minimize bleeding and other procedurerelated complications. The heart was exposed through a median sternotomy. In all cases the original outflow graft (Dacron fabric, not preclotted) of the pump system was replaced by a sealed vascular graft (Vascutek graft, Vascutek, Renfrewshire, Scotland), and the inflow conduit was preclotted with fibrin glue (Tissucol fibrin glue, Immuno, Vienna, Austria). A pocket was then prepared in the left upper quadrant of the abdominal wall, anterior to the posterior rectus muscle sheath. Cardiopulmonary bypass was instituted by cannulating the ascending aorta for arterial perfusion and the superior and inferior venae cavae for venous return. A vent was placed inside the left ventricular cavity via the right upper pulmonary vein. After the outflow graft was anastomosed to the ascending aorta, cardiopulmonary bypass was started for insertion of the left ventricular apical conduit. The aorta was crossclamped and the heart arrested with use of either crystalloid (Bretschneider solution) or cold blood cardioplegia according to Buckberg. ${ }^{6}$ After ventriculotomy at the left ventricular apex was completed, the inflow conduit was replaced and the pump and the grafts were carefully evacuated of air and continuous pumping begun. To prevent adhesions the outflow graft was covered with a sheath of polytetrafluoroethylene. ${ }^{*}$ The abdominal facia was extended by a resorbable mesh (Vicryl mesh, Ethicon, Inc., Somerville, N.J.) in six patients to provide suitable space for accommodation of the pump.

Anticoagulation protocol. The perioperative anticoagulation treatment consisted of 2 million units of aprotinin and regular heparinization ( $300 \mathrm{IU} / \mathrm{kg}$ body weight) for cardiopulmonary bypass. Systemic heparinization was

\footnotetext{
* Gore-Tex Surgical Membrane. Gore-Tex is a registered trademark of W. L. Gore \& Associates, Putzbrunn, Germany.
}

fully antagonized with protamine sulfate at the end of cardiopulmonary bypass.

In the postoperative phase intravenous administration of heparin was started when the activated partial thromboplastin time (aPTT) was less than 50 seconds or the activated coagulation time was less than 140 seconds. Heparinization was considered sufficient if the aPTT ranged between 60 and 80 seconds. When patients were mobilized, the anticoagulation treatment was changed to oral phenprocoumon (Marcumar), maintaining the prothrombin time level at an international normalized ratio of 3.0 to $4.5 .^{7}$ Antithrombin III was substituted when levels fell below $80 \%$. The protocol for postoperative anticoagulation was changed after a thromboembolic event in patient 7 . It now includes heparin intravenously and then subcutaneously, acetylsalicylic acid $100 \mathrm{mg} / \mathrm{d}$, and dipyridamole $75 \mathrm{mg} / 8$ hourly.

After operation the following tests were frequently used to monitor anticoagulation therapy: aPTT, prothrombin time, platelet count, fibrinogen, activated coagulation time, antithrombin III, $\alpha$-2-haptoglobin, and hemopexin-S. For evaluation of platelet function a specific test, "bleeding time ex vivo," according to Kratzer and Born ${ }^{8}$ was applied (Thrombostat 4000, Baxter, Unterschleissheim, Germany).

Statistics. Data are given as mean values \pm standard deviation. The $\chi^{2}$ test was used to calculate significant differences between groups; Fisher's exact test was used in small sample sizes. Yates' correction for continuity was done. A $p$ value of 0.05 was taken as the level of significance.

\section{Results}

Hemodynamic data. The hemodynamic situation was significantly improved after implantation of the LVAS (Figs. 2 and 3). Mean arterial pressure increased from $70 \pm 11 \mathrm{~mm} \mathrm{Hg}$ to $87 \pm 13 \mathrm{~mm} \mathrm{Hg}$ $(p<0.05)$. Mean cardiac index, $1.71 \pm 0.42$ $\mathrm{L} / \mathrm{min} / \mathrm{m}^{2}$ before Novacor LVAS implantation, rose to $3.23 \pm 0.74 \mathrm{~L} / \mathrm{min} / \mathrm{m}^{2} 24$ hours after the start of mechanical circulatory support $(p<0.01)$. Average pulmonary capillary wedge pressure was $27.1 \pm 4.4$ 


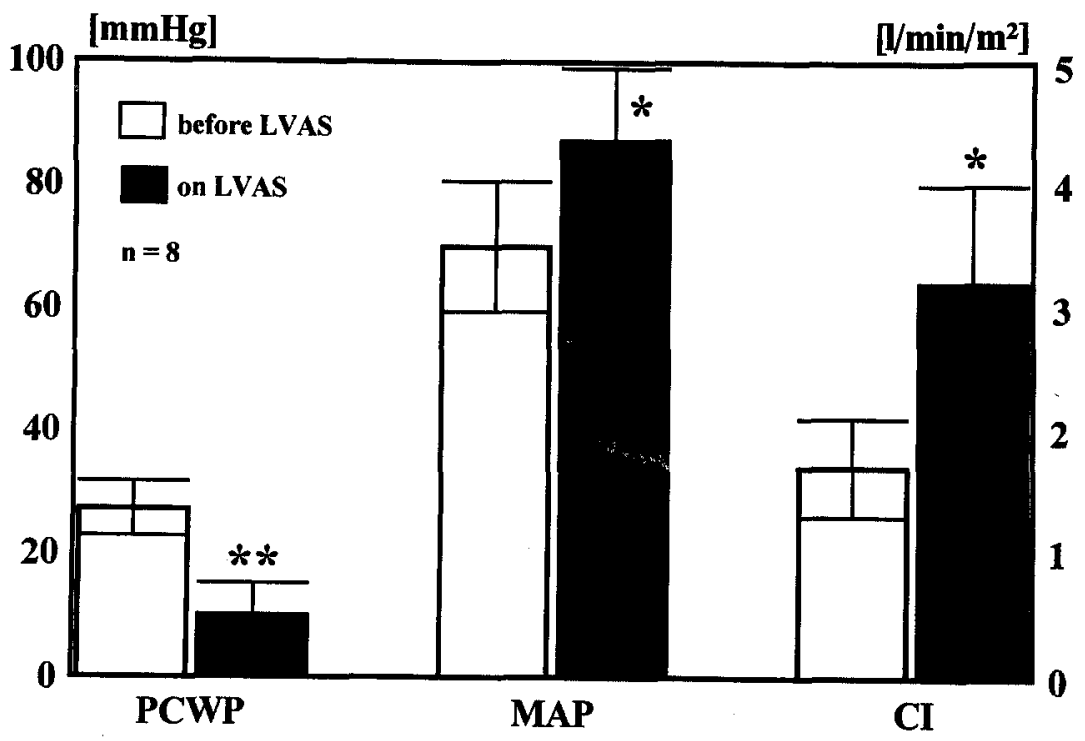

Fig. 2. Function of the left side of the heart in patients before and 24 hours after implantation of Novacor LVAS. $P C W P$, Pulmonary capillary wedge pressure ( $\mathrm{mm} \mathrm{Hg}$ ); $M A P$, mean arterial pressure $(\mathrm{mm} \mathrm{Hg}$ ); $C I$, cardiac index $\left(\mathrm{L} / \mathrm{min} / \mathrm{m}^{2}\right)$; asterisk, $p<0.05$.

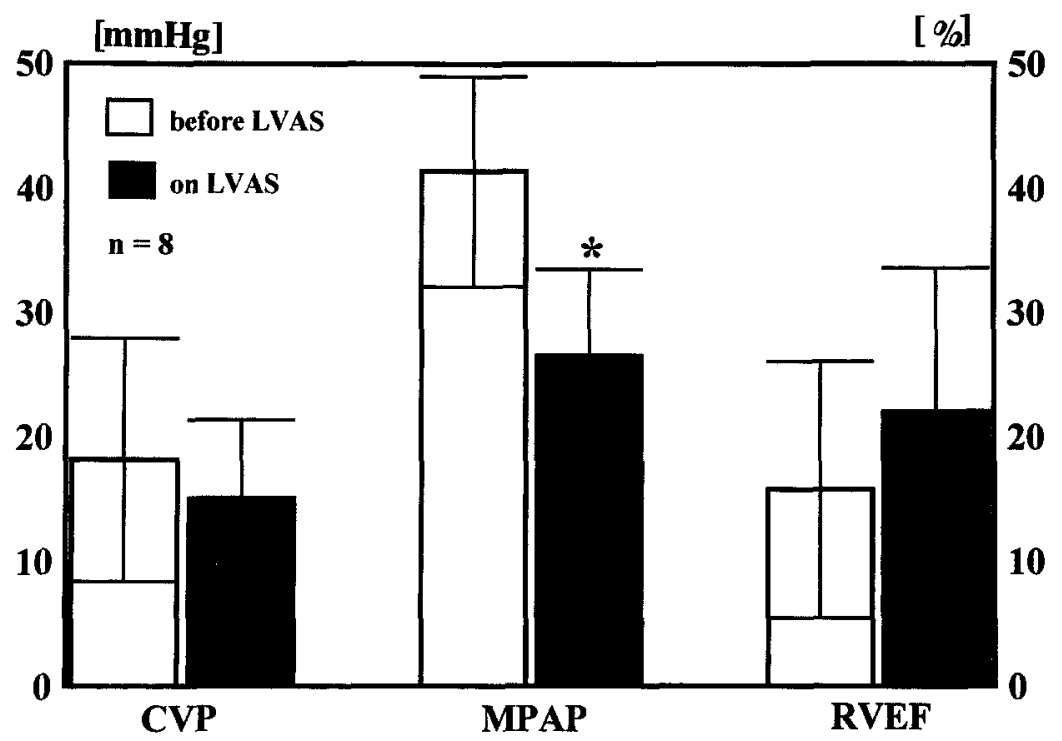

Fig. 3. Function of the right side of the heart in patients before and 24 hours after implantation of Novacor LVAS. CVP, Central venous pressure (mm $\mathrm{Hg}) ; M P A P$, mean pulmonary artery pressure (mm $\mathrm{Hg}) ; R V E F$, right ventricular ejection fraction (\%); asterisk, $p<0.05$.

$\mathrm{mm} \mathrm{Hg}$ (range 22 to $34 \mathrm{~mm} \mathrm{Hg}$ ) before operation and decreased to $9.9 \pm 5.2 \mathrm{~mm} \mathrm{Hg}$ (range 4 to 13 $\mathrm{mm} \mathrm{Hg}$ after operation $(p<0.05)$.

Central venous pressure was $18.1 \pm 9.8 \mathrm{~mm} \mathrm{Hg}$ on average before Novacor LVAS implantation and $15.0 \pm 6.3 \mathrm{~mm} \mathrm{Hg}$ during left ventricular support (not significant). Mean pulmonary artery pressure decreased from $41 \pm 9 \mathrm{~mm} \mathrm{Hg}$ before operation to $27 \pm 6 \mathrm{~mm} \mathrm{Hg}$ after operation $(p<0.05)$. Calculation of right ventricular ejection fraction could be done in seven patients: the mean value was $16.7 \% \pm$ $10.3 \%$ (range $4 \%$ to $30 \%$ ) before operation and increased during mechanical left ventricular support to $22.0 \% \pm 11.6 \%$ (range $10 \%$ to $45 \%$ ). However, 


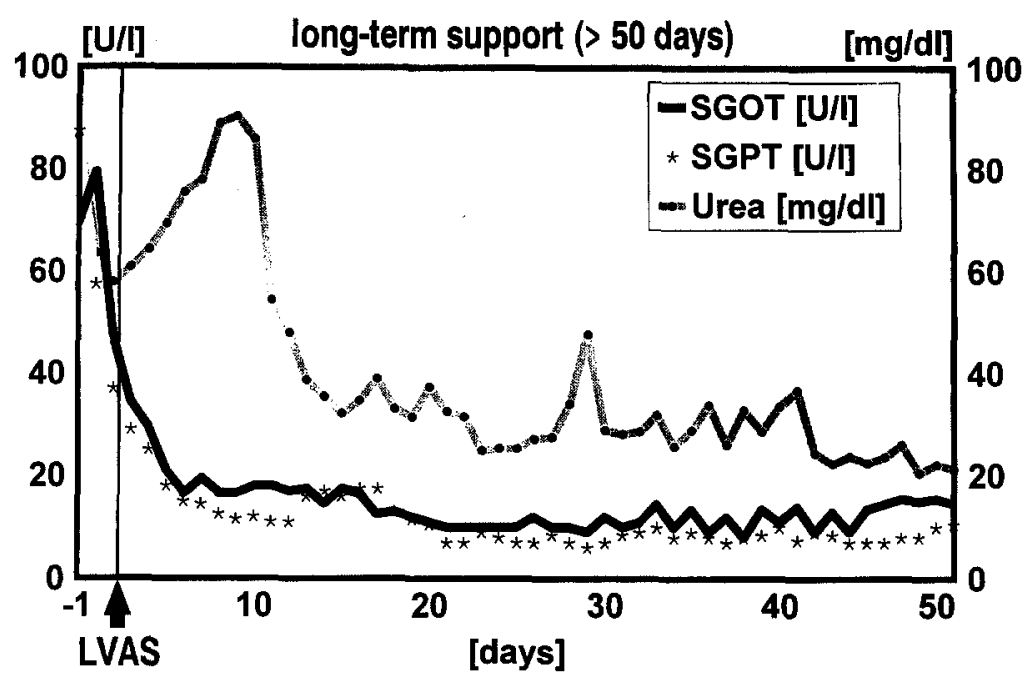

Fig. 4. Time course of hepatic and renal function of three patients who received long-term support with the Novacor LVAS. Parameters normalized on average after 20 days of mechanical circulatory support. $S G O T$, aspartate aminotransferase; $S G P T$, alanine aminotransferase.

this increase was not statistically significant. There was no significant difference in heart rate before and after operation: average $120 \pm 17$ beats $/ \mathrm{min}$ and $117 \pm 7$ beats/min, respectively. Mean values of all the parameters mentioned did not differ significantly when evaluated immediately before heart transplantation. In patients who received LVAS support for more than 20 days, hepatic and renal function was improved before transplantation (Fig. 4).

Recovery period. Three patients were kept on the regular ward after initial recovery in the intensive care unit. Patients were mobilized and were eventually able to walk to the hospital park and to the shopping area. Trips to sightseeing areas in town were arranged together with the LVAS operators. A program for physical activities was initiated in cooperation with the physiotherapists. A daily "activities schedule" was arranged for each patient to provide psychologic support. This included physical activities, games (such as chess), and visits from relatives and medical students involved in the clinical study.

Complications. Only one patient acquired a documented serious pulmonary infection caused by Legionella bozemanii. He was treated successfully with erythromycin, ciprofloxacin, and fluconazole.

A tendency of prolonged bleeding was observed in most of the patients. Surgical intervention was necessary in five patients; three had a cardiac tamponade within the first postoperative week and a rethoracotomy because of cardiac tamponade was done in two patients who received long-term support. One patient underwent revision of the subcutaneous area of the abdominal pocket because of a hematoma.

Two patients who received long-term support had an embolic accident during left ventricular circulatory support (Table II). These occurred on days 40 (severe impairment of visual function) and 31 (hemiparesis) of support, respectively. The possible source of this thromboembolism was found after explanation of the pump. Various amounts of thrombotic material were found on the proximal and distal sides of the inflow pericardial valve prostheses (Fig. 5). The neurologic lesions resolved completely in one patient and only a minor neurologic deficit remained at the time of transplant in the other patient.

Outcome. Five patients received short-term $(<7$ days) and three patients long-term ( $\geq 50$ days) support (Table II). Orthotopic heart transplantation was done in all eight patients. One patient died 2 days after transplantation because of unspecific donor heart failure. The remaining seven patients are alive and well 1 to 25 months after heart transplantation. Four patients returned to work, one patient was already retired before the operations, one patient is currently in rehabilitation, and one patient is in the hospital awaiting discharge 2 weeks after heart transplantation. 
Volume 109, Number 1

Table II. Complications and outcome

\begin{tabular}{clclc}
\hline $\begin{array}{c}\text { Patient } \\
\text { No. }\end{array}$ & \multicolumn{1}{c}{ Complications } & $\begin{array}{c}\text { Days of } \\
\text { LVAS } \\
\text { support }\end{array}$ & \multicolumn{1}{c}{ Outcome } & $\begin{array}{c}\text { Time since } \\
\text { HTx (mos) }\end{array}$ \\
\hline 1 & CT day 1, RF, sternum open & 3 & HTx, alive, working & 25 \\
2 & RF, sternum open & 2 & HTx, died day 2 postop. & - \\
3 & CT day 2 & 5 & HTx, alive, working & 21 \\
4 & CT day 3 & 7 & HTx, alive, retired & 18 \\
5 & CT day 8, CVA day 40 & 52 & HTx, alive, working & 12 \\
6 & None & 5 & HTx, alive, working & 11 \\
7 & CVA day 31, WR, lung infection & 50 & HTx, alive, rehabilitation & 6 \\
8 & CT days 15 and 22, RF, WR & 122 & HTx, alive, in hospital & 1 \\
\hline
\end{tabular}

$C T$, Cardiac tamponade; $H T x$, heart transplantation; $R F$, renal failure; $C V A$, cerebrovascular accident; $W R$, wound revision.

\section{Discussion}

This series of patients who underwent bridge to cardiac transplantation with the Novacor LVAS shows that mechanical circulatory support can be done with low mortality while providing significant hemodynamic improvement and physical rehabilitation. Hemodynamic data showed that parameters of function of the left side of the heart can be improved significantly within 24 hours of the institution of circulatory support. In the majority of patients pump operation in synchronous counterpulsation could be achieved immediately after Novacor LVAS implantation and provided a pump output ranging between 4.5 and $8.0 \mathrm{~L} / \mathrm{min}$. As a result impaired renal function improved rapidly (within hours or within the first 2 postoperative days). Continuous hemofiltration was necessary only in two patients in the early postoperative phase. Pennington and associates ${ }^{9}$ reported in a series of 44 cases that used different methods of circulatory support that there is excellent functional recovery and survival of such patients.

Despite severe impairment, function of the right side of the heart improved significantly during isolated left ventricular support. Implantation of a right ventricular assist device was not indicated. In a clinical study Kormos and colleagues ${ }^{10}$ demonstrated an improvement of the function of the right side of the heart in most patients after implantation of the Novacor system.

In our center the Novacor LVAS has proved to be a highly reliable system for assisting the failing heart. No technical faults have been detected during operation. The patients who received long-term support were trained to manage their own power supply: they were able to change and recharge batteries and prepare for out-of-hospital walks on their own. Pump noise was not a problem for the

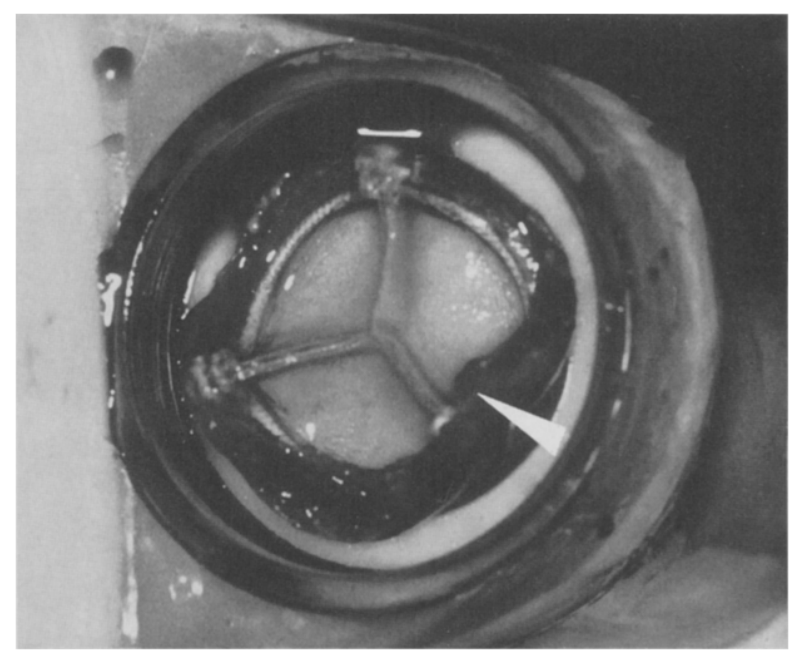

Fig. 5. Photograph showing explanted inflow bovine pericardial valve prosthesis after 52 days of implantation. Distal side reveals areas of thrombotic deposits (arrow).

patients. Development of the wearable system was a major step forward in providing mobility for patients in need of long-term support and improved quality of life during the waiting period.

Thromboembolism remains the major threat during mechanical circulatory support. A reason for the thromboembolic event in one patient was the normalization of platelet function in the absence of acetylsalicylic acid or dipyridamole treatment during a period of low pump output $(<3.5 \mathrm{~L} / \mathrm{min})$ caused by hypovolemia. Because a triple drug therapy consisting of heparin (intravenously or subcutaneously), acetylsalicylic acid, and dipyridamole has been used in the most recent two patients, no more thromboembolic complications have been experienced. Some fibrinous depositions on the prosthetic inflow valve have been frequently observed. Multiple factors in- 
cluding coagulation state, flow, and thrombotic deposition within the prosthetic device or native heart may contribute to thromboembolic complications.

The question as to whether a patient who has a residual deficit after a cerebrovascular event should receive transplantation before complete rehabilitation may be an issue. However, after 10 to 14 days, patients should be able to undergo cardiopulmonary bypass with minimal risk.

In summary, hemodynamic and metabolic recompensation of patients who receive the Novacor LVAS is possible within a relatively short period of support. Postoperative anticoagulation is important to minimize the risk of thromboembolic complications. Early mobilization and physical activities are easier to do in patients with use of the wearable system.

We gratefully thank the medical students Mr. Willi Röll and Mr. Gernot Schindler for their support and Mr. Steeger and Mrs. von Yorck from the Department of Photography and Graphics at Grosshadern Hospital.

\section{REFERENCES}

1. Ramasamy N, Portner PM. Results with bridge to transplant and chronic support. In: Ott RA, Gutfinger $D E$, Gazzaniga $A B$, eds. Cardiac surgery: mechanical cardiac assist. Philadelphia: Hanley \& Belfus, 1993: 363-77.

2. Hetzer R, Hennig E, Schiessler A, Friedel N, Warnecke $H$, Adt $M$. Mechanical circulatory support and heart transplantation. J Heart Lung Transplant 1992; 11:175-81.

3. Kormos RL, Murali S, Dew MA, et al. Chronic mechanical circulatory support: rehabilitation, low morbidity, and superior survival. Ann Thorac Surg 1994;57:51-8.

4. McCarthy PM, Portner PM, Tobler GH, Starnes VA, Ramasamy N, Oyer PE. Clinical experience with the Novacor ventricular assist system. J THORAC CARDIOVASC SURg 1991;102:578-87.

5. Oyer PE, Stinson EB, Portner PM, Ream AK, Shumway NE. Development of a totally implantable electrically actuated left ventricular assist system. Am J Surg 1980;140:17-24.

6. Buckberg GD. Strategies and logic of cardioplegic delivery to prevent, avoid, and reverse ischemic and reperfusion damage. $\mathbf{J}$ ThORAC CARDIOvasc SuRG 1987;88:726-41.

7. Szukalski EA, Reedy JE, Pennington DG, Swartz MT, McBride LR, Miller LW. Oral anticoagulation in patients with ventricular assist devices. ASAIO Trans 1990;36:M700-3.

8. Kratzer M, Born GV. Simulation of primary hemostasis in vitro. Hemostasis 1985;15:357-62.
9. Pennington DG, McBride LR, Peigh PS, Miller LW, Swartz MT. Eight years' experience with bridging to cardiac transplantation. J THORAC CARDIOVASC SuRG 1994;107:472-81.

10. Kormos RL, Gasior T, Antaki J, et al. Evaluation of right ventricular function during clinical left ventricular assistance. ASAIO Trans 1989;35:547-50.

\section{Discussion}

Dr. Eric A. Rose (New York, N.Y.). I congratulate you on these results and your illustration of the concept originally proposed by Bob Frazier and Victor Poirier that a vented system that is not totally implantable allows a reasonable quality of life in these patients.

I have two questions. One is the issue of anticoagulation. I think it still remains speculative that the addition of antiplatelet agents to the already vigorous anticoagulation regimen that you described will be effective in preventing thromboembolism in these patients.

Second, is the incidence of thromboembolism with the Novacor device low enough to consider the use of this type of device for long-term support?

Dr. Vetter. I did not want to give the impression that adding anti-platelet aggregation medication will prevent thromboembolism. In the two patients who had a cerebrovascular accident there were additional negative influences present. In one patient there was, as a result of hypovolemia, a rather low pump output situation that might have contributed to the appearance of thrombus formation at the inflow valve. The other patient was in atrial fibrillation at the time of the cerebrovascular accident.

Another patient was supported by the device for 122 days and received triple drug therapy (heparin intravenously, acetylsalicylic acid, and dipyridamole). He went through bridging without thromboembolism. Therefore I think that the Novacor LVAS in its present design is a suitable device for patients who need long-term support. Whether it is a device to send patients home with, I do not know yet. I think monitoring problems have to be solved in the future.

Dr. Mortimer J. Buckley (Boston, Mass.). May I ask how you handled the right ventricular failure? In the Novacor LVAS, as I understand it, you cannot put in a biventricular system.

Dr. Vetter. As I showed, our first four patients used the system only for a short term. The reason for that was in three of these patients there was poor right ventricular function. Right ventricular ejection fraction was $4 \%$. We always wanted to manage without institution of a right ventricular support system because at that time we did not have the Berlin Heart (Berlin Heart, Fehling Medical, Berlin, Germany), and we did not have heparinized circuits for the Bio-Medicus pump (Bio-Medicus, Inc., Eden Prairie, Minn.). We would rather use medications, such as prostacycline, to improve postoperatively function of the right side of the heart. Therefore in these patients we went on with transplantation. One can see, however, timing is important for such patients, and we showed that a short time of bridging does not mean the outcome must be bad. 